\title{
LED-to-LED wireless communication between divers
}

\author{
Fabio Leccese ${ }^{1}$, Giuseppe Schirripa Spagnolo² \\ ${ }^{1}$ Dipartimento di Scienze, Università degli Studi "Roma Tre", via della Vasca Navale n. 84, 00146 Roma, Italy \\ 2 Dipartimento di Matematica e Fisica, Università degli Studi "Roma Tre", via della Vasca Navale n. 84, 00146 Roma, Italy
}

\section{ABSTRACT}

For military divers, having a robust, secure, and undetectable wireless communication system available is a fundamental element. Wireless intercoms using acoustic waves are currently used. These systems, even if reliable, have the defect of being easily identifiable and detectable. Visible light can pass through sea water. Therefore, light can be used to develop short-range wireless communication systems. To realize secure close-range underwater wireless communication, the Underwater Optical Wireless Communication (UOWC) can be a valid alternative to acoustic wireless communication. UOWC is not a new idea, but the problem of the presence of sunlight and the possibility of using near-ultraviolet radiation (near-UV) has not been adequately addressed in the literature yet. In military applications, the possibility of using invisible optical radiation can be of great interest. In this paper, a feasibility study is carried out to demonstrate that UOWC can be performed using near-ultraviolet radiation. The proposed system can be useful for wireless voice communications between military divers as well as amateur divers.

\section{Section: RESEARCH PAPER}

Keywords: underwater communication; visible light communications; optical wireless communication, bidirectional communication; LED; photo detector Citation: Fabio Leccese, Giuseppe Schirripa Spagnolo, LED-to-LED wireless communication between divers, Acta IMEKO, vol. 10, no. 4, article 15, December 2021, identifier: IMEKO-ACTA-10 (2021)-04-15

Section Editor: Francesco Lamonaca, University of Calabria, Italy

Received October 4, 2020; In final form December 6, 2021; Published December 2021

Copyright: This is an open-access article distributed under the terms of the Creative Commons Attribution 3.0 License, which permits unrestricted use, distribution, and reproduction in any medium, provided the original author and source are credited.

Corresponding author: Fabio Leccese, e-mail: fabio.leccese@uniroma3.it

\section{INTRODUCTION}

Currently, the use of wireless communications is very common in a wide range of terrestrial devices. In the underwater world, wireless information transfer is of great interest to the military. It plays an important role in military raids carried out by a team of divers. For safety and to coordinate actions, a secure and reliable bidirectional communication system is useful. Nowadays, underwater wireless communications are implemented almost exclusively via acoustic waves due to their relatively low attenuation [1], [2].

Communication by measuring light waves (Visible Light Communication - VLC) is a technology that employments light spectra from 400 to $700 \mathrm{~nm}$ as data carriers. VLC techniques transmit data wirelessly by pulsing visible light. This new technology, called Li-Fi, can replace the Wi-Fi connection, based on radio frequency waves [3]-[6].

Beer's law is usually utilized to correlate the absorption of diffuse light to the properties of the medium through which the light is traveling. From a mathematical point of view, we can write [7], [8]:

$$
P(\lambda, r)=P_{0} \cdot \mathrm{e}^{-K_{\mathrm{d}}(\lambda) \cdot r},
$$

where $P_{0}$ is the initial transmitted power, $P(\lambda, r)$ is the residual power after the light beam with wavelength $\lambda$ has traveled the distance $r$ through the medium with Diffuse Attenuation Coefficient $K_{\mathrm{d}}(\lambda)$. Figure 1 shows the attenuation coefficient of three typical ocean waters I, II and III and five coastal waters 1 , 3, 5, 7 and 9; the lower numbers correspond to clearer waters. The classification corresponding of Jerlov water types [9]-[11].

Light with longer wavelengths is absorbed more quickly than that with shorter wavelengths. Because of this, the higher energy light with short wavelengths, such as blue-green, is able to penetrate more deeply. In open ocean, below $100 \mathrm{~m}$ depth, only blue-green radiation is present [12]. However, the blue component of sunlight can also reach depths of up to $1000 \mathrm{~m}$; although the quantity is so low that photosynthesis is not allowed [12]. Figure 1 shows that the minimal absorption is between $460 \mathrm{~nm}$ and $580 \mathrm{~nm}$; depending on the type of water. Therefore, VLC technology is extensively studied as an alternative solution for short range underwater communication links [13]-[28].

Really, underwater optical wireless communication (UOWC) is not a new idea. After the pioneering works of the 1980s [29][31], in 2009, Doniec et al. [32] have developed a 5-meter 


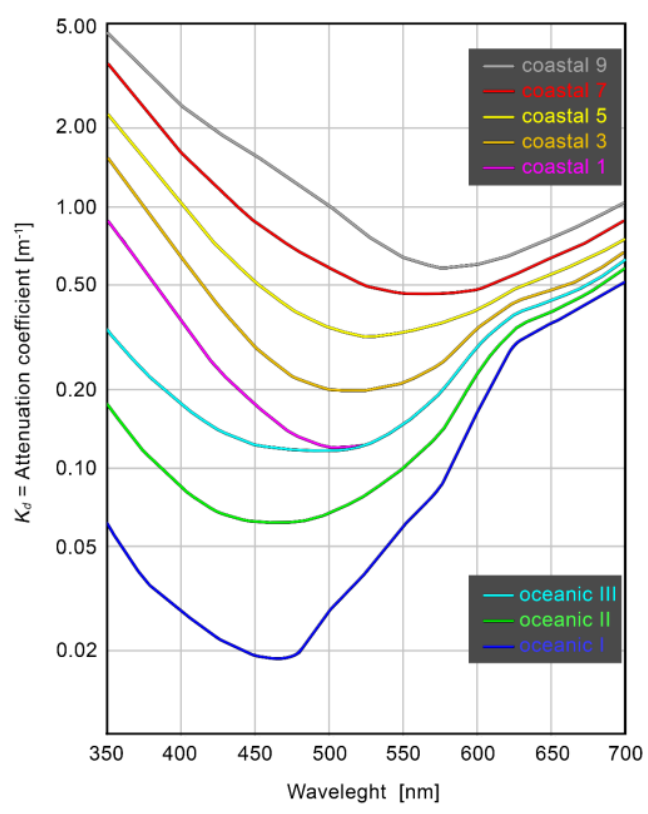

Figure 1. Diffuse attenuation coefficient $K_{d}(\lambda)$ for several oceanic and coastal water types according Jerlov classification. Curves obtained from the data present in [9]-[11].

underwater wireless optical communication link (called AquaOptical) with a $1 \mathrm{Mbps}$ data rate. Later in 2015, Rust et al. [33] have implemented an UOWC system for use in remote controlled vehicles (ROVs) used for the inspection of nuclear power plants. In addition, some systems are currently commercially available [34]-[37]. Unfortunately, the performance of UOWC is currently limited to short range [38]. However, in some specific situations, short-range communication is more than enough. On the other hand, there are circumstances where short range communication is needed without the need for large bandwidth. A typical example is the communication between divers.

For communication between divers, the most common form is through hand signals [39], and underwater writing slates [40], [41]. Figure 2 shows two example of standard diver hand signals and a dive slate.

The dialect of the diver's hand signals includes only plain and precise gestures easily identifiable. This allows only simple communications and require extensive memorization. On the
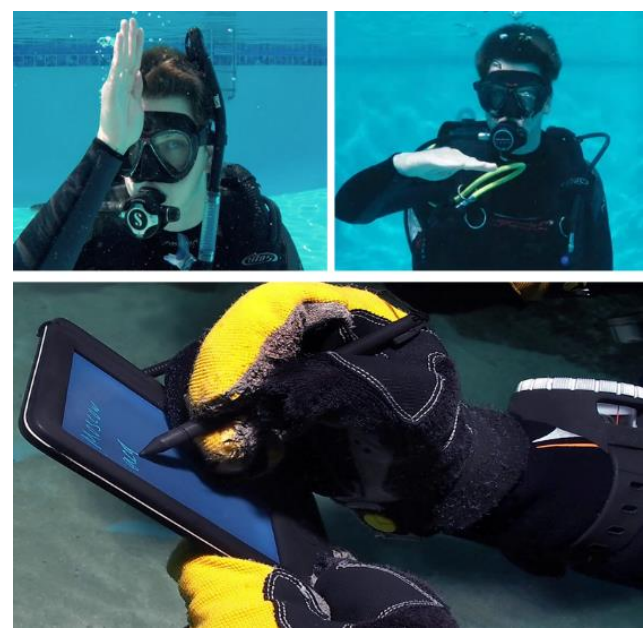

Figure 2. Examples of Standard Diver Hand Signals and of a Dive Slate.

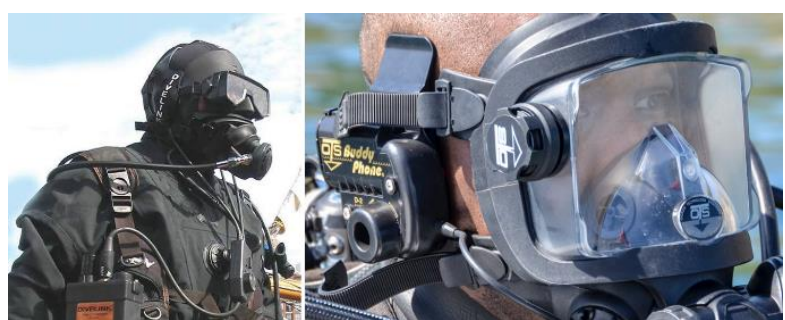

Figure 3. Examples of Standard Diver Hand Signals and of a Dive Slate.

other hand, slates do not allow communication in real time; it takes time to write and to attract the attention of the underwater partners.

Recently, full face diving masks with snorkels have been introduced that allow the diver to breathe and speak normally inside the mask [42], [43]. For this type of masks, reliable underwater intercoms have been developed to allow divers to talk each other underwater [44], [45]. A transducer is attached to the diver's face mask. This transducer converts the voice into an ultrasonic signal. Each diver of the team has an ultrasonic receiver, which accepts the signal and converts it back to a sound that the divers can hear, enabling communication. This type of communication system can be used by amateur or professional divers. Figure 3 shows two commercially available systems of underwater intercoms.

During military raids with divers, it is very important that the various components of the command can communicate with each other. Unluckily, hand signs do not allow for complex information to be communicated, and the use of dive slate can be incompatible with the times. An audio communication is essential for complex communications needed in military actions.

Another key problem in military communications is that they must be secure and undetectable. Unfortunately, the acoustic waves that travel in water are easily detectable. Therefore, their use is not convenient during critical military missions. In this scenario, UOWC is a good alternative to acoustic communication [46]. It has the advantage that it cannot be intercepted. This specific application does not require long range and high band communications. Therefore, the usable systems can be simple, small, lightweight and with low power. Figure 4 shows a typical UOWC between divers. The information could be transmitted through a special torch and be captured by sensors positioned on the diving suit.

Unfortunately, communications with visible light suffer from noise generated by solar background noise or artificial light sources. Special precautions must be taken to minimize this noise [47]. It would be convenient to implement UOWC systems that use optical radiation different from that normal present in water.

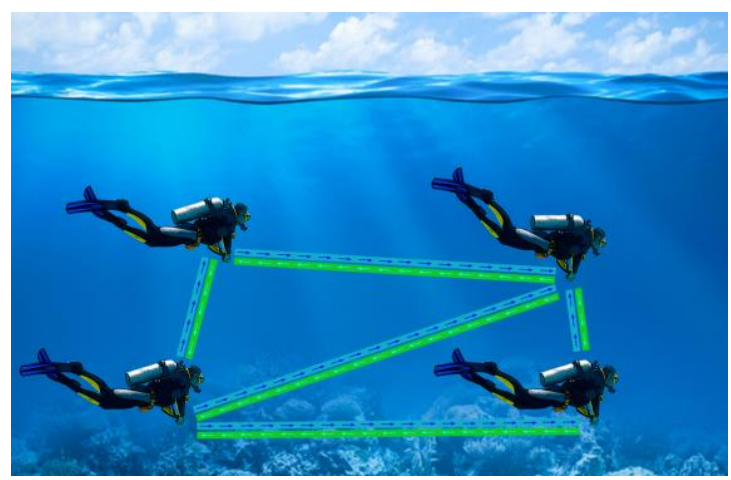

Figure 4. Optical communication between divers. 
In addition, during communications between the military divers it would be useful to use light not visible from normal video surveillance systems.

The main purpose of the paper is to verify the feasibility of a communication system that can be used by the military divers. The system must be simple, robust, consuming few energy and not affected by ambient light, and, above all, difficult to detect and/or intercept by video surveillance systems sensitive to visible radiation. To obtain these performances it is necessary to avoid the use of blue-green radiation, present in the solar radiation that penetrates into the water. In addition, visible radiation must be avoided, which is easily detectable at night by underwater video surveillance systems.

In this paper, an underwater near-ultraviolet light communication is proposed. The proposed system uses as emitter (Tx) an UV LED with peak wavelength $\lambda=385 \mathrm{~nm}$ and half width $\Delta \lambda=15 \mathrm{~nm}$. Instead, a photodiode, made with an LED like the one used as a transmitter, is used as a receiver $(\mathrm{Rx})$. This system is intrinsically low sensitive to ambient light and produces an invisible communication channel. Since there are video surveillance systems that have good sensitivity in the bluegreen spectral band [48], the use of radiation in the near UV allows having a relatively good penetration of the radiation into the water and at the same time to be invisible to these video surveillance systems.

The system works well in short range communications where large bandwidth is not required. For example, if we are only interested to speech transmission, a bandwidth of $32 \mathrm{kbps}$ is generally acceptable. With this type of communication, it is possible to create simple, small, light, robust and energy efficient systems.

\section{UNDERWATER COMMUNICATIONS BY UV-A RADIATION}

A part of the solar radiation spectrum overlaps with the radiation commonly used for the Visible Light Communication (VLC) [49]. Therefore, it is very difficult to attenuate the effects of sunlight without loss of useful signal. In the presence of sunlight, the receivers see very high white noise and can often go into saturation. To try to solve the problems deriving from solar radiation (in general of the ambient lights present), it is possible to use near-ultraviolet radiation for the communication channel.

Generally, solar intensity decreases with depth. By examining how light is absorbed in water (see Figure 1), we see that the best wavelengths to use in UOWC are $450 \mathrm{~nm}-500 \mathrm{~nm}$ for clear waters and $570 \mathrm{~nm}-600 \mathrm{~nm}$ for coastal waters. This same attenuation is also true for the solar spectrum [50]. In any case, at a depth of a few meters, the solar radiation in the near ultraviolet is practically absent. Furthermore, in relatively clear waters this radiation is relatively poorly attenuated especially in ocean waters but less in coastal waters (according to Figure 1). For these reasons, submarine communication systems, which use UV-A band communication channels, are extremely interesting.

We must also observe two other important characteristics of optical communication that uses the near ultraviolet. This communication channel is difficult to detect and intercept, particularly attractive feature for military applications. Furthermore, the use of ultraviolet radiation allows wireless connections to be made without requiring perfect alignment between transmitter and receiver (NLOS UV scattering communication) [51], [52]. Very useful characteristic for wireless transmission between moving objects.

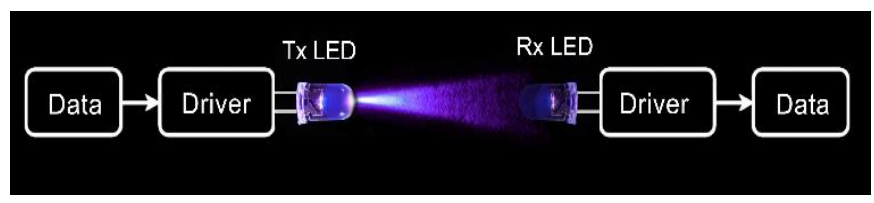

Figure 5. Basic LED used as light emitter and receiver.

\section{LED USABLE AS LIGHT DETECTOR}

In addition to emitting light, LEDs can be employed also as light sensor/detector [53]-[60]. Figure 5 schematically, shows this application In addition, the LED can also be used as a temperature sensor [61].

To verify the possibility of underwater communication through UV radiation, we have chosen to use a reverse-polarized LED as a detector. The choice was made to have an inexpensive photodetector that is not very sensitive to the light radiations present in the environment; without the need for filters that cut visible radiation. LED can be also used as Avalanche PhotoDiode (APD) [62], [63].

Unlike normal photodiodes, LEDs can detect a narrow band of wavelengths, they are spectrally selective detectors. In contrast, normal photodiodes have a wide spectral response and require costly filters to detect a specific wavelength. Both LEDs and photodiodes have sensitivity stable over time. However, the filters have a limited life.

In a $\mathrm{p}-\mathrm{n}$ diode, inside the junction, there are free charges generated by thermal energy. When a $\mathrm{p}$-n junction diode is reverse biased, these charges are accelerated. This movement of charges produces the reverse current of the diode. If the reverse polarization potential is increased, the free charges can acquire enough energy to ionize some atoms of the crystal lattice. This ionization produces additional free charges. Moreover, these additional charges are accelerated by the polarization potential. This creates an avalanche effect, producing a large reverse current (breakdown current). The polarization voltage at which this arises is called Zener potential [64].

If you want to use an LED as light detector, generally, the photocurrents generated are linear but very small. In UOWC applications, we have currents in the range of nano amps. Therefore, for their correct subsequent signal processing, it is necessary to transform the detect current into a suitable voltage. For this operation, transimpedance amplifiers are commonly used [65]. The amplitude of the signal received by the LED, and subsequently amplified by transimpedance amplifiers, depends on many external parameters. For this reason, the transmitted optical signal must be suitably digitized and modulated. Our system uses a modulation format based on pulse width modulation (PWM).

\section{UV LED-TO-LED COMMUNICATION SYSTEM}

In underwater optical wireless transmission, the signal reaching the receiver has low intensity. For this reason, extensive studies are underway to use very sensitive detectors such as Avalanche PhotoDiode (APD) or Single Photon Avalanche Diode [66]-[75]. With the use of very responsive photosensors, the problem of the presence of ambient light is very important [76].

With the use of a LED-to-LED transmission system that uses UV LEDs, it is possible to implement an underwater 


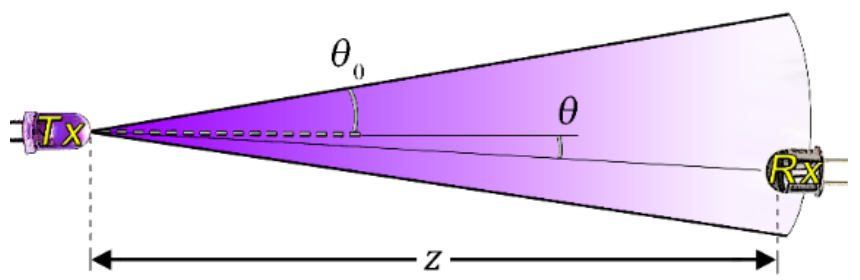

Figure 6. Seawater light transmission model.

communication system with invisible radiation that is not very sensitive to ambient light.

LED-to-LED communication systems are characterized by low cost, low complexity and, above all, low energy consumption. On the other hand, they can be used only when the exchange of messages occurs at a small distance without the need for large bandwidth [76], [77].

As already mentioned, underwater, practically, ultraviolet radiation is absent. Therefore, using UV LED as light emitter and a UV LED, used as APD, as receiver allows to have a system that is not very sensitive to environment light; an LED can detect radiation with a wavelength slightly shorter than or equal to that emitted (Internal photoelectric effect) [56], [57], [78].

The same type of LED can be used as a receiver and as a transmitter. The use of the same type of LED is useful in half duplex communication systems; the same LED can be used as a transmitter or as a receiver. In this work, we have used a Bivar UV5TZ-385-30 LED as a transmitter and receiver [79]. This LED has viewing angle of $30^{\circ}$ and an aperture area of $25 \cdot 10^{-6} \mathrm{~m}^{2}$.

Seawater light transmission model is shown in Figure 6. The optical power on the receiver can be written as [80]-[83]:

$$
P_{\mathrm{Rx}}=P_{\mathrm{Tx}} \cdot \eta_{\mathrm{Tx}} \cdot \eta_{R x} \cdot \exp \left[-\frac{K_{\mathrm{d}}(\lambda) \cdot z}{\cos \theta}\right] \cdot \frac{A_{\mathrm{R}_{\mathrm{x}}} \cdot \cos \theta}{2 \pi \cdot z^{2}\left(1-\cos \theta_{0}\right)},
$$

where $P_{\mathrm{Tx}}$ is the transmitted power, $\eta_{\mathrm{Tx}}$ and $\eta_{\mathrm{Rx}}$ are the optical efficiencies of the $T x$ and $R x$ correspondingly, $K_{\mathrm{d}}(\lambda)$ is the attenuation coefficient, $z$ is the perpendicular distance between the $T x$ plane and the $R x$ plane, $\theta_{0}$ is the $T x$ beam divergence angle, $\theta$ is the angle between the perpendicular to the $R x$ plane and the $T x-R x$ trajectory, and $A_{\mathrm{R}_{\mathrm{X}}}$ is the receiver aperture area.

In our system, they experimentally verified that the received signal is correctly reconstructed if the misalignment is $\theta<20^{\circ}$.

The transmitter LED was driven with $25 \mathrm{~mA}$ by means of a pulse generator. While the current generated by the LED used as a receiver, reverse biased with a voltage of $15 \mathrm{~V}$, was read through a transimpedance amplifier. Two Ultralow Noise Precision High Speed Op Amps [84] were used to implement the transimpedance amplifier. The amplifier, as shown in Figure 7, is made in two states. This is to be able to obtain a passband greater than $100 \mathrm{kHz}$.

The Rx and Tx LEDs, together with the relative control electronics, were inserted in a tank filled with real seawater (water taken from the Tyrrhenian coast - Anzio - Italy). The LEDs are placed at $50 \mathrm{~cm}$ and facing one towards the other.

Figure 8 shows the experimental setup used for the tests. The experimental tests were carried out in the laboratory and outdoors in different configurations of ambient brightness. Figure 8(a) shows the system working in laboratory. Figure 8(b) shows the system working outdoors in full sun. All the tests carried out confirmed that the system is practically insensitive to ambient light (both artificial and natural).
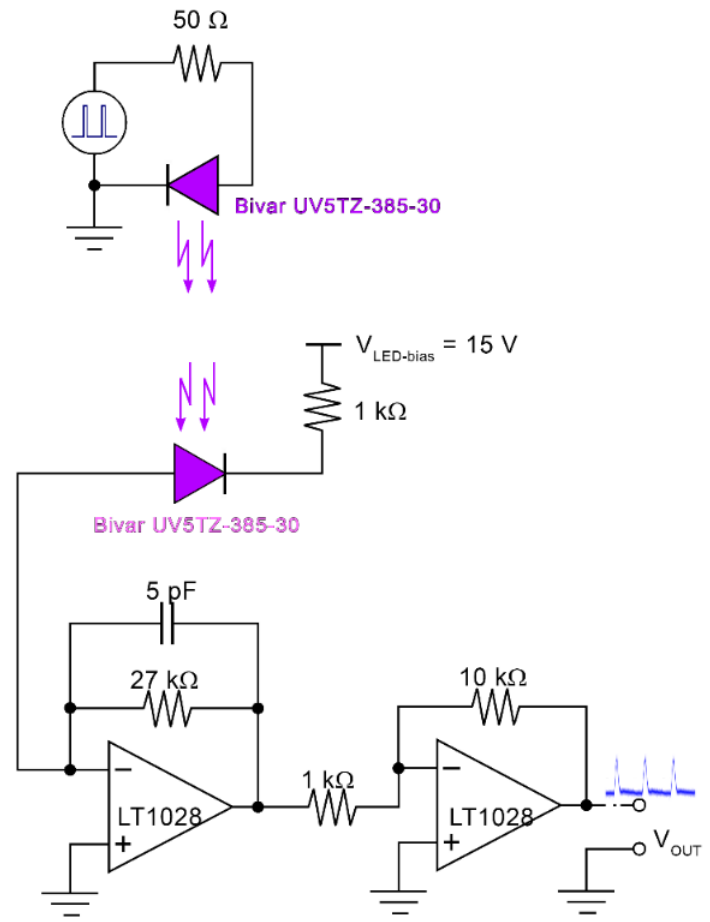

Figure 7. Rx and Tx LED driver circuit.

The experimental setup is realized to be able to obtain three different lengths of the optical channel. The different lengths of the optical path are obtained by means of mirrors, as shown in Figure 9.

The Figure 10 show the signal used to drive the Tx LED (cyan trace) and the corresponding output signal ( $\left.V_{\text {out }}\right)$ from the $\mathrm{Rx}$ circuit (yellow trace).

The implemented system uses only one LED as a transmitter and another as a receiver. In our application, there are no restrictions on using a LED cluster to transmit information. As well as it can be useful to use LED array to receive the signal. By using many diodes as $\mathrm{Tx}$, as well as $\mathrm{Rx}$, systems with better performance can be obtained. We used the simplest possible configuration as the aim was to demonstrate the possibility of
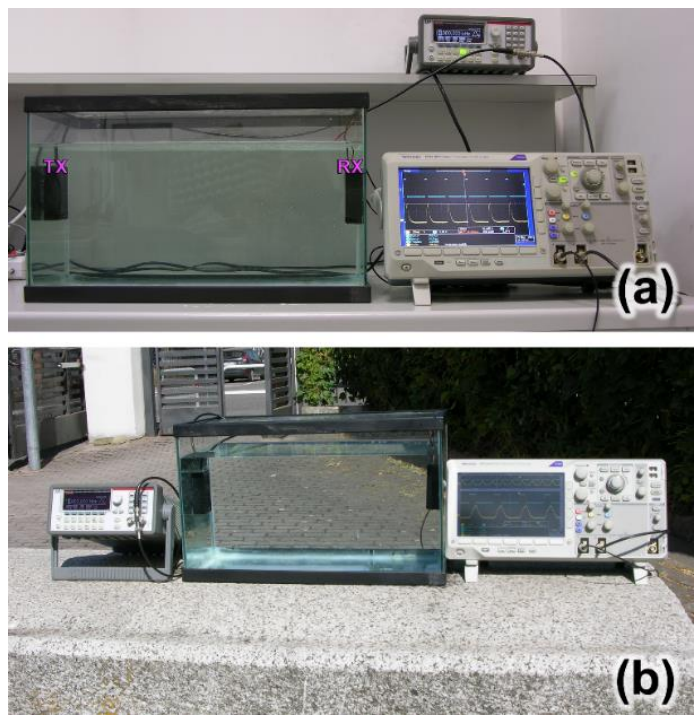

Figure 8. Experimental setup used for the tests: (a) system working in laboratory; (b) system working outdoors. 

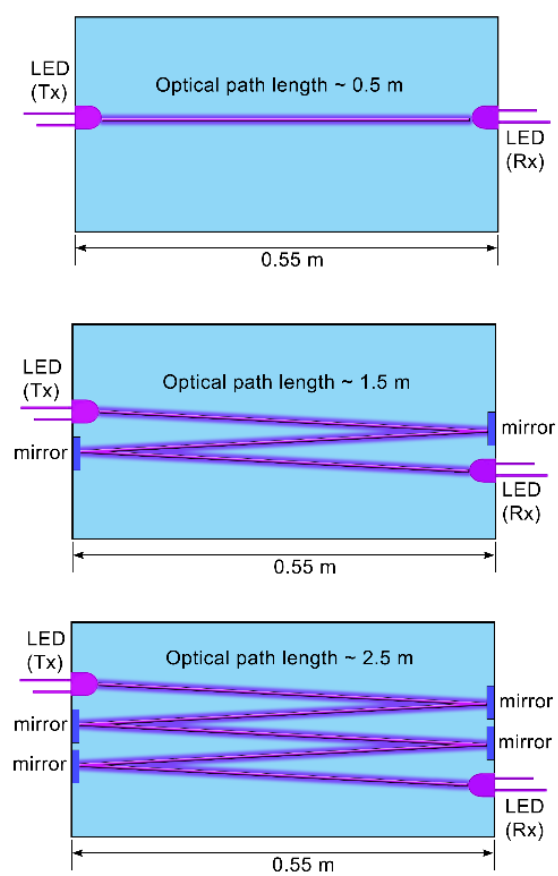

Figure 9. Schematic of the water canal. The different optical path is obtained with the help of mirrors.

implementing an underwater LED-to-LED transmission using near ultraviolet radiation.

\section{SYSTEM DESCRIPTION}

In any reliable communication system, data must be suitably modulated. Modulation consists in varying one or more properties of a relatively high frequency signal (carrier).
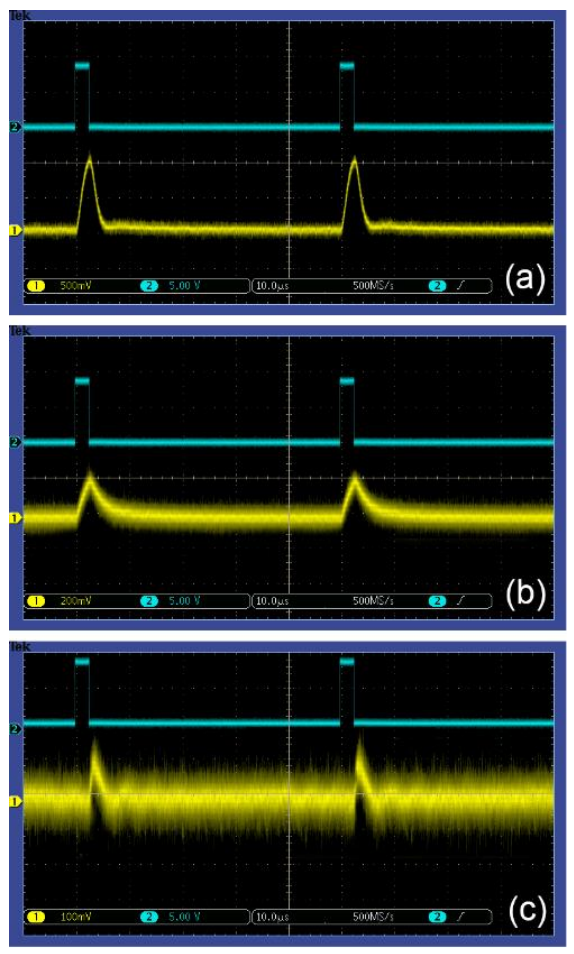

Figure 10. The cyan line represents the signal used to drive the Tx LED. The yellow line represents the corresponding Rx output signal. (a) Distance between transmitter and receiver $0.5 \mathrm{~m}$. (b) Distance between transmitter and receiver $1.5 \mathrm{~m}$. (c) Distance between transmitter and receiver $2.5 \mathrm{~m}$.

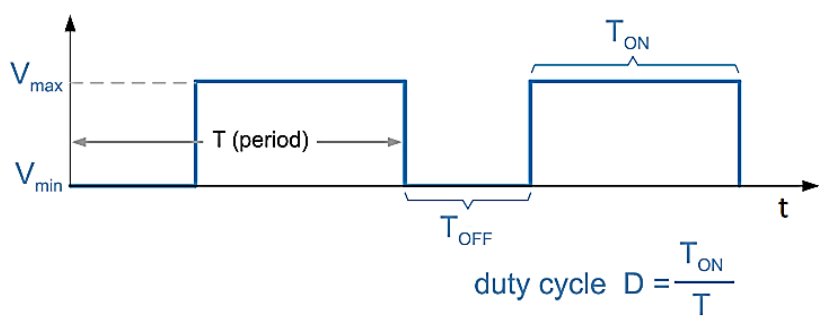

Figure 11. PWM signal. Square wave with constant frequency and amplitude by variable duty cycle.

We used PWM modulation to implement our system. Furthermore, considering that high sound quality is not required for audio communication between divers, this type of modulation is more than enough to test the feasibility of wireless audio communication via UV-A optical channel. Obviously, more performing, and more robust modulation systems with respect to noise can be used.

The PWM consists of the information signal (in our case the audio signal) that causes the modification of the time duration of the pulse carrier. This pulse signal turns the transmitter LED on and off at the rate of the carrier's frequency. In other word, with PWM technique we change the duty cycle of a square wave with constant frequency and amplitude; as shown in Figure 11.

The average value of a PWM signal, period by period, can be expressed as:

$V_{\text {average }}=\frac{1}{T}\left(\int_{0}^{D \cdot T} V_{\max } \cdot d t+\int_{D \cdot T}^{T} V_{\min } \cdot d t\right)$.

If $V_{\min }=0$, the Equation (3), can be simplified as:

$V_{\text {average }}=D \cdot V_{\text {max }}$.

Equation (4) indicates that if the amplitude of the carrier is constant (along a period), the average value of the PWM signal is directly proportional to the duty cycle. If the duty cycle is proportional to the information to be transmitted, it can be extracted through a simple averaging operation on the PWM signal. Average is easily obtainable through opportune low pass filtering.

To verify the real possibility of realizing an audio communication, we have respectively coupled a modulator and a demodulator to the LED transmitter and to the LED receiver [85]-[87].

The block diagram of our audio modulator and LED driver is shown in Figure 12. This LED driver has a restricted baud rate. The main reason is the limited switching speed of silicon devices. A maximum data rate of $100 \mathrm{kbps}$ can be achieved with this driver. In any case, this speed of data transmission is more than enough to implement an excellent audio connection. The PWM is achieved by means of a timing circuits NE555 [88] and a comparator LT1011 [89]. Our circuit is powered with $6.5 \mathrm{~V}$ and produces a sawtooth waveform with frequency of approximately $100 \mathrm{kHz}$ and peak to peak voltage about $4.3 \mathrm{~V}$.

The sawtooth waveform is applied to the non-inverting input of the comparator. The audio signal works as the reference voltage and is applied to the inverting input. To realize a duty cycle of $50 \%$, the audio signal is offset at the average voltage of the sawtooth waveform ( $1 / 3$ of the power supply voltage). The comparator output is equal to the supply voltage when the sawtooth output is a higher voltage than the audio signal. 


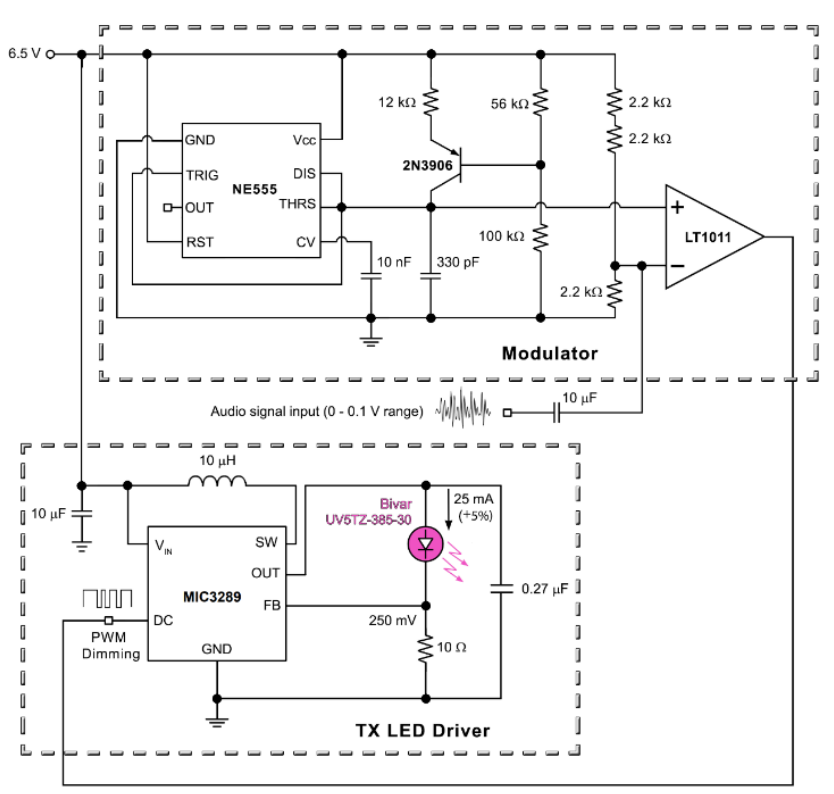

Figure 12. Audio modulator and LED driver.

The LED driver is based on the integrated MIC3289 [90]. It is a PWM boost-switching regulator that is optimized for constant-current LED driver applications. Figure 16 shows the input and output signals in a Pulse Width Modulation process.

To recover the transmitted audio, a receiver unit, mainly composed of photodetector and signal conditioning devices, is used. The photodiode receives the transmitted optical signal and converts the optical signals into the electrical signals. Then, the electrical signal is fed into the recovery circuits and PWM demodulator. Figure 14 shows the block diagram of the receiver unit.

The transimpedance amplifier (shown in the Figure 7) is coupled with a low pass filter. This filter, with cut-off frequency about $1 \mathrm{MHz}$, uses to reduce the high frequency noise present at the transimpedance amplifier output. The output signal of filter has an amplitude that depends on many external parameters, as well as the distance and misalignment between transmitter and receiver. To obtain a correct reconstruction of the PWM signal, a comparator with variable threshold is used. By means of an integrator circuit, a voltage proportional to the average value of the amplitude of the received signal is obtained. This voltage is used as the threshold of the comparator. The integrator that was used provides an average signal at the output, which is about one third of the amplitude of the signal coming from the filter. In this way, the reconstruction of the PWM signal is obtained which is practically independent of the amplitude of the signal received by the LED used as photodiode. Finally, the reconstructed PWM

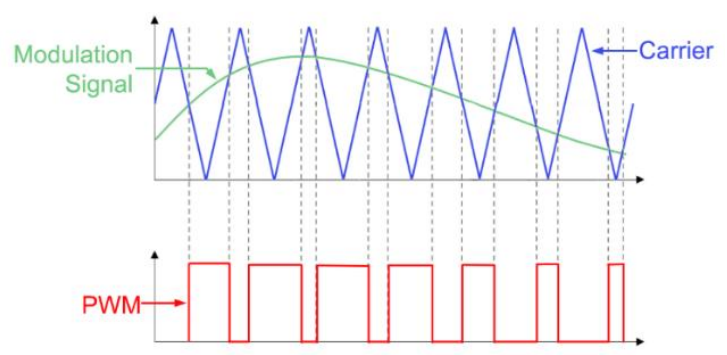

Figure 13. Input and output signals in a Pulse Width Modulation process.
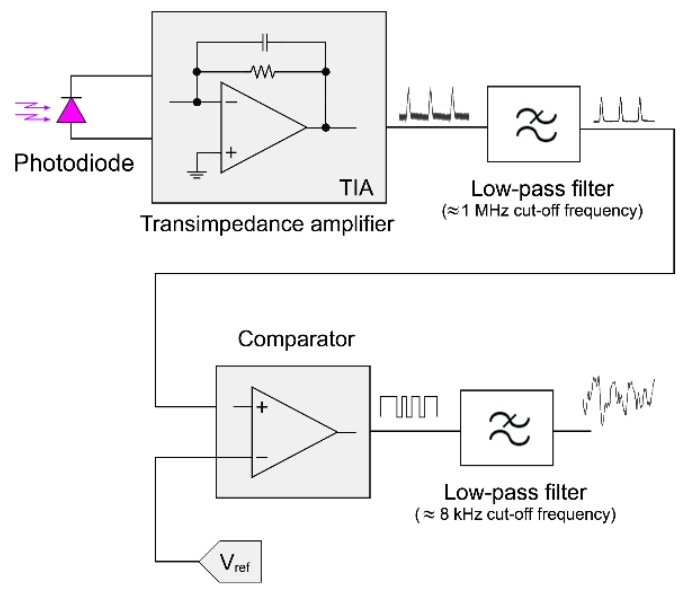

Figure 14. Input and output signals in a Pulse Width Modulation process

signal (signal with constant amplitude and variable duty cycle) is demodulate by a low pass filter with a cutoff frequency of $8 \mathrm{kHz}$.

Instead, Figure 15 shows the schematic drawing of the receiving unit.

A low pass filter is sufficient to decode the audio information contained in the PWM signal. By choosing a low-pass filter with an appropriate cut-off frequency, it will be possible to remove the high-frequency component in the PWM signal while keeping only the low-frequency signal (the audio information). Our demodulator is a 4th order Butterworth low pass filter. It consists of two non-identical 2 nd order low pass filter. The human ear can perceive sounds with frequencies between $20 \mathrm{~Hz}$ and $20 \mathrm{kHz}$. In any case, the human voice produces sound that are confined to within $8 \mathrm{kHz}$. Therefore, for verbal communications, a low-pass filter with a cut-off frequency around $8 \mathrm{kHz}$ is sufficient.

The 4th order Butterworth filter we use has a cutoff frequency of approximately $7.8 \mathrm{kHz}$. Therefore, it is irrelevant for all the sound frequencies emitted by the human voice. On the other hand, at $100 \mathrm{kHz}$, the filter has an attenuation of $83 \mathrm{~dB}$. This

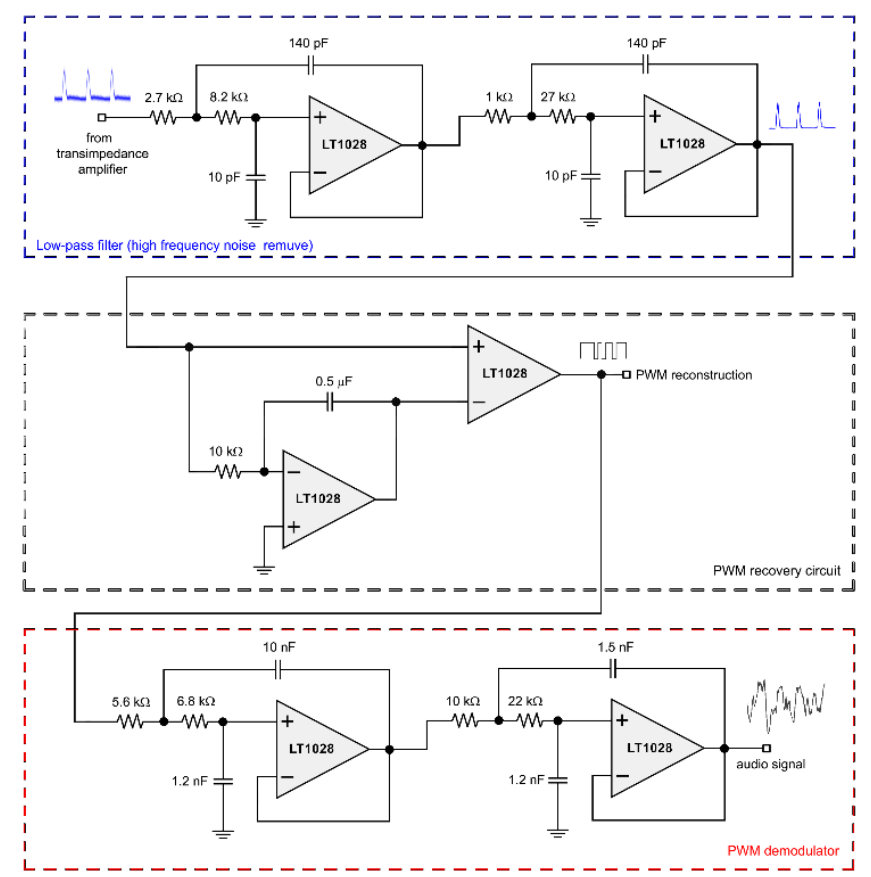

Figure 15. Schematic of the optical receiver circuit. 


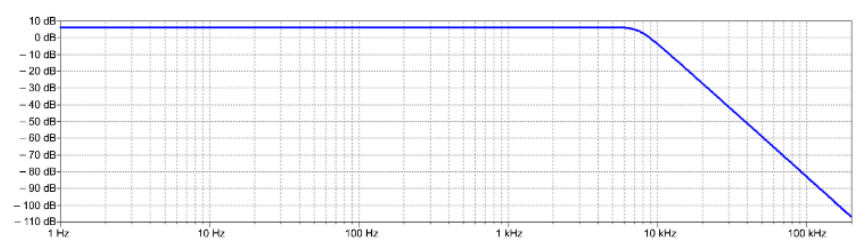

Figure 16. Our $4^{\text {th }}$ order Butterworth Low pass filter frequency response.

indicates that the high frequency carrier is highly suppressed. Figure 16 shows the frequency response of the filter used to retrieve the audio information from the PWM signal

Preliminary tests were conducted to verify the real applicability of our system in underwater wireless voice transmission.

First, a $4 \mathrm{kHz}$ tone was used to check the entire modulation, optical transmission, optical detection, and demodulation system. In Figure 17(a) trace 1 (yellow) is the sinusoidal $4 \mathrm{kHz}$ tone going into the transmitter. While trace 2 (blue) shows the PWM modulation used to drive the Tx LED current. In Figure 17(b) trace 2 (blue) shows the reconstructed PWM signal in the receiving unit. Finally, trace (1) (yellow) of Figure 17(b) shows the reconstruction of the sinusoid at $4 \mathrm{kHz}$.

The reconstruction of the sinusoid is more than acceptable, even if there is the presence of "noise", related to the harmonics of the carrier signal.

Subsequently, the system was tested by transmitting an audio speech signal. With $2.5 \mathrm{~m}$ between $\mathrm{Tx}$ and $\mathrm{Rx}$ the speech transmitted is perfectly understandable. Figure 18 shows the audio tracks, spectrograms, and frequency analysis of the transmitted audio signal and of the message reconstructed downstream of the receiver.

\section{CONCLUSIONS}

Underwater Optical Wireless Communication (UOWC) has recently emerged as a unique opportunity. Many studies are present in the literature, however underwater optical communication via near-ultraviolet (UV-A) radiation is not addressed. In this paper, we have shown that in short range when broadband communication is not needed, it is possible to implement a UOWC system that makes use of UV-a radiation. A UV underwater optical wireless audio transceiver was proposed for wireless communication in close range between divers.

We have also verified that this system can be realized via an LED-LED connection. This makes the system simple, economical, light, compact and, above all, not energy-intensive.

The study is mainly designed for military applications. In military applications, it is very important to have systems that cannot be intercepted and possibly not easily identifiable. In addition to have low energy consuming systems. For these reasons, we have developed a system that uses non-visible optical
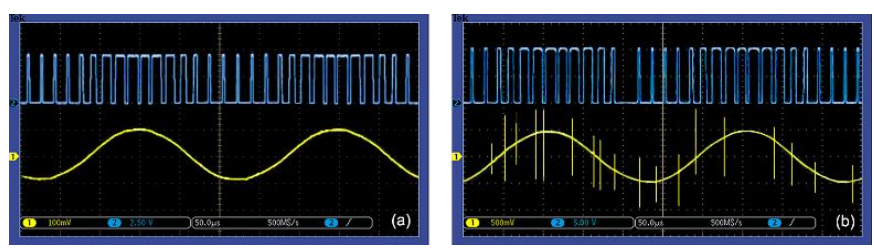

Figure 17. (a) Pulse-width Modulation Waveform. Trace yellow: tone of $4 \mathrm{kHz}$; trace blue relative PWM modulation. (b) Trace blue: PWM signal recovered in the Rx unit; trace yellow $4 \mathrm{kHz}$ tone present at Rx output.
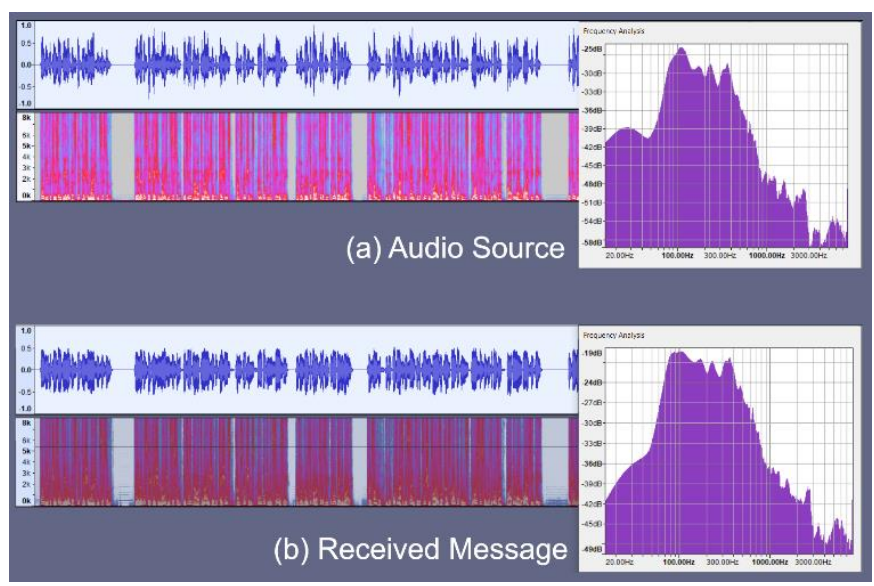

Figure 18. (a) audio track, spectrograms, and frequency analysis of the transmitted audio. (b) audio track, spectrograms, and frequency analysis of the of the retrieved audio signal. Figures obtained by Audacity ${ }^{\circledR}$ software [91].

radiation and LED-to-LED transmission, which is energy efficient.

However, considering the simplicity and cost-effectiveness of the developed system, it can easily be used for communications between amateur divers.

In our study, we faced the problem of verifying the feasibility of transmitting a signal, with sufficient bandwidth to transmit an audio signal, at a distance of about $2.5 / 3$ meters. Further studies and tests in the real marine environment are needed.

\section{REFERENCES}

[1] H. Sari, B. Woodward, Digital underwater voice communications. In: R. S. H. Istepanian, M. Stojanovic (eds) Underwater Acoustic Digital Signal Processing and Communication Systems. Springer, Boston, MA. 2002. DOI: $10.1007 / 978-1-4757-3617-54$

[2] J. W. Giles, I. N. Bankman, Underwater optical communications systems. Part 2: basic design considerations. Proceedings of the MILCOM 2005 -IEEE Military Communications Conference. Atlantic City, NJ, USA, 17-20 October 2005.

DOI: $10.1109 /$ MILCOM.2005.1605919

[3] H. Haas, L. Yin, Y. Wang, C. Chen, What is LiFi?, Journal of Lightwave Technology 34(6) (2016), pp. 1533-1544.

DOI: $10.1109 /$ JLT.2015.2510021

[4] M. Uysal, C. Capsoni, Z. Ghassemlooy, A. Boucouvalas, E. Udvary, Optical wireless communications: an emerging technology. Springer: New York, NY (USA), 2016.

DOI: $10.1007 / 978-3-319-30201-0$

[5] M. Z. Chowdhury, M. Shahjalal, M. Hasan, Y. M. Jang, The Role of Optical Wireless Communication Technologies in 5G/6G and Io'T Solutions: Prospects, Directions, and Challenges, Applied Sciences 9(20) (2019) art. no. 4367.

DOI: $10.3390 /$ app9204367

[6] G. Schirripa Spagnolo, L. Cozzella, F. Leccese, S. Sangiovanni, L. Podestà, E. Piuzzi, Optical Wireless Communication and Li-Fi: a New Infrastructure for Wireless Communication in Saving Energy Era, in Proceedings of 2020 IEEE International Workshop on Metrology for Industry 4.0 \& IoT, Roma, Italy, 2020, pp. 674-678. DOI: $10.1109 /$ MetroInd4.0IoT48571.2020.9138180

[7] H. G. Pfeiffer, H. A. Liebhafsky, The origins of Beer's law, Journal of Chemical Education 28(3) (1951), pp. 123. DOI: $10.1021 / \mathrm{ed} 028 \mathrm{p} 123$

[8] H. R. Gordon, Can the Lambert-Beer law be applied to the diffuse attenuation coefficient of ocean water? Limnology and Oceanography 34(8) (1989), pp. 1389-1409.

DOI: $\underline{10.4319 / 10.1989 .34 .8 .1389}$ 
[9] N. G. Jerlov, Irraiance, Marine optics vol. 14, ch.10 (1968), pp.115132, Elsevier Oceanography Series, Amsterdam, Netherlands. DOI: $10.1016 /$ S0422-9894(08)70929-2

[10] M. G. Solonenko, C. D. Mobley, Inherent optical properties of Jerlov Water types, Appl. Opt. 54(17) (2015), pp. 5392-5401. DOI: $10.1364 / A O .54 .005392$

[11] N. G. Jerlov, Optical Classification of Ocean Water. Physical Aspects of Light in the Sea, edited by John E. Tyler, Honolulu: University of Hawaii Press, 2021, pp. 45-50. DOI: $10.1515 / 9780824884918-009$

[12] J. T. O. Kirk, Light and photosynthesis in aquatic ecosystems, Cambridge, UK: Cambridge University Press, 2013. DOI: $10.1017 / \mathrm{CBO} 9781139168212$

[13] MIT News. Advancing undersea optical communications. Online [Accessed 05 December 2021]. http://news.mit.edu/2018/advancing-undersea-opticalcommunications- 0817

[14] C. M. G. Gussen, P. S. R. Diniz, M. L. R. Campos, W. A. Martins, F. M. Costa, J. N. Gois, A survey of underwater wireless communication technologies. J. of Commun. and Info. Sys. 31(1) 2016, pp. 242-255.

DOI: $10.14209 /$ jcis.2016.22

[15] H. Kaushal, G. Kaddoum, Underwater Optical Wireless Communication. IEEE Access 4 (2016), pp. 1518-1547. DOI: $10.1109 /$ ACCESS.2016.2552538

[16] C. Shen, Y. Guo, H. M. Oubei, T. K. Ng, G. Liu, K. H. Park, K T. Ho, M. S. Alouini, B. S. Ooi, 20-meter underwater wireless optical communication link with 1.5 Gbps data rate. Optics Express 24(22) (2016), pp. 25502-25509. DOI: $10.1364 /$ OE.24.025502

[17] J. Xu, Y. Song, X. Yu, A. Lin, M. Kong, J. Han, N. Deng, Underwater wireless transmission of high-speed QAM-OFDM signals using a compact red-light laser. Optics express 24(8) (2016), pp. 8097-8109.

DOI: $\underline{10.1364 / O E .24 .008097}$

[18] C. Wang, H. Y. Yu, Zhu, A long distance underwater visible Light communication system with single photon avalanche diode, IEEE Photonics Journal 8(5) (2016) art. no. 7906311.

DOI: 10.1109/JPHOT.2016.2602330

[19] R. Ji, S. Wang, Q. Liu, W. Lu, High-speed visible light communications: enabling technologies and state of the art. Appl. Sci. 8(4) (2018) art. no. 589 DOI: $10.3390 /$ app 8040589

[20] H. M. Oubei, C. Shen, A. Kammoun, E. Zedini, K. H. Park, X Sun, G. Liu, C. H. Kang, T. K. Ng, N. S. Alouini, Light based underwater wireless communications. Japanese Journal of Applied Physics 57(8S2) (2018), 08PA06.

DOI: $10.7567 /$ JJAP.57.08PA06

[21] M. F. Ali, D. N. K. Jayakody, Y. A. Chursin, S. Affes, S. Dmitry, Recent advances and future directions on underwater wireless communications, Archives of Computational Methods in Engineering 27 (2020), pp. 1379-1412. DOI: $10.1007 /$ s11831-019-09354-8

[22] G. D. Roumelas, H. E. Nistazakis, A. N. Stassinakis, C. K. Volos, A. D. Tsigopoulos, Underwater optical wireless communications with chromatic dispersion and time jitter, Computation 7(3) (2019) art. no. 35. DOI: $10.3390 /$ computation 7030035

[23] N. Saeed, A. Celik, T. Y. Al-Naffouri, M. S. Alouini, Underwater optical wireless communications, networking, and localization: A survey, Ad Hoc Networks 94 (2019) art. no. 101935. DOI: 10.1016/i.adhoc.2019.101935

[24] Z. Hong, Q. Yan, Z. Li, T. Zhan, Y. Wang, Photon-counting underwater optical wireless communication for reliable video transmission using joint source-channel coding based on distributed compressive sensing, Sensors 19(5) (2019) art. no. 1042.

DOI: $10.3390 / \mathrm{s} 19051042$
[25] G. Schirripa Spagnolo, L. Cozzella, F. Leccese, Underwater optical wireless communications: Overview, Sensors 20 (2020) art. no. 2261.

DOI: $10.3390 / \mathrm{s} 20082261$

[26] S. Zhu, X. Chen, X. Liu, G. Zhang, P. Tian, Recent progress in and perspectives of underwater wireless optical communication, Progress in Quantum Electronics 73 (2020) art. no. 100274. DOI: $10.1016 /$ i.pquantelec.2020.100274

[27] G. Schirripa Spagnolo, L. Cozella, F. Leccese, A Brief Survey on Underwater Optical Wireless Communications. In 2020 IMEKO TC-19 International Workshop on Metrology for the Sea, Naples, Italy, October 5-7, 2020, pp. 79-84. Online [Accessed 05 December 2021] https://www.imeko.org/publications/tc19-Metrosea2020/IMEKO-TC19-MetroSea-2020-15.pdf

[28] J. Sticklus, P. A. Hoeher, R. Röttgers, Optical underwater communication: The potential of using converted green LEDs in coastal waters. IEEE Journal of Oceanic Engineering 44(2) (2018), pp. 535-547. DOI: $10.1109 / \mathrm{JOE} .2018 .2816838$

[29] T. Wiener, S. Karp, The Role of Blue/Green Laser Systems in strategic submarine communications, IEEE Transactions on Communications 28(9) (1980), pp. 1602-1607.

DOI: $10.1109 /$ TCOM.1980.1094858

[30] L. W. E. Wright, Blue-green lasers for submarine communications, Naval Engineers Journal 95(3) (1983), pp. 173-177. DOI: $10.1111 / \mathrm{i} .1559-3584.1983 . t b 01635 . \mathrm{x}$

[31] R. E. Chatham, Blue-green lasers for submarine communications, in Conference on Lasers and Electro-Optics, G. Bjorklund, E. Hinkley, P. Moulton, and D. Pinnow, eds., OSA Technical Digest (Optical Society of America, 1986), paper WM1. DOI: $10.1364 /$ CLEO.1986.WM1

[32] M. Doniec, I. Vasilescu, M. Chitre, C. Detweiler, M. HoffmannKuhnt, D. Rus, Aquaoptical: A lightweight device for high-rate long-range underwater point-to-point communication, Mar. Technol. Soc. J. 44 (2010), pp. 1-6.

DOI: $10.4031 /$ MTSJ.44.4.6

[33] I. C. Rust, H. H. Asada, A dual-use visible light approach to integrated communication and localization of underwater robots with application to non-destructive nuclear reactor inspection. In Proceedings of the IEEE International Conference on Robotics and Automation, Saint Paul, MN, USA, 14-18 May 2012; pp. 2445-2450.

DOI: $10.1109 /$ ICRA.2012.6224718

[34] Hydromea. Online [Accessed 05 December 2021]. https://www.hydromea.com

[35] Acquatec Group. Online [Accessed 05 December 2021]. https://www.aquatecgroup.com

[36] Marine link. Online [Accessed 05 December 2021]. https://www.marine-link.com

[37] Sonardyne. Online [Accessed 05 December 2021]. https://www.sonardyne.com

[38] B. Cochenour, K. Dunn, A. Laux, L. Mullen, Experimental measurements of the magnitude and phase response of highfrequency modulated light underwater, Appl. Opt. 56(14) (2017), pp. 4019-4024.

DOI: $\underline{10.1364 / A O .56 .004019}$

[39] Recreational Scuba Training Council (RSTC), Common Hand Signals for Recreational Scuba Diving, 2015. Online [Accessed 05 December 2021].

http://www.neadc.org/CommonHandSignalsforScubaDiving.pd $\underline{f}$

[40] Underwater Slate. Online [Accessed 05 December 2021] https://www.mares.com/en/underwater-slate

[41] Electronic Underwater Slate. Online [Accessed 05 December 2021]. https://duslate.com

[42] O. Rusoke-Dierich, Basic Diving Equipment. In: Diving Medicine 2018, pp. 15-19, Springer, Cham. DOI: $10.1007 / 978-3-319-73836-922$ 
[43] Neptune Space Predator T-Divers Full Face Mask-Free Shipping. OCEAN REEF Inc. - 2510 Island View Way - Vista, California 92081 USA, 2021. Online [Accessed 05 December 2021].

https://diving.oceanreefgroup.com/wp-

content/uploads/sites/3/2018/10/Neptune-SpacePREDATOR-T-DIVERS-rel-1.3.pdf

[44] Ocean Technology Systems, Wireless Underwater Communications. Online [Accessed 05 December 2021]. https://www.oceantechnologysystems.com/learningcenter/through-water-communications/

[45] DIVELINK Underwater Communications Ltd. Online [Accessed 05 December 2021]. http://www.divelink.net/purchase/aga/8-home

[46] H. A. Nowak, Underwater LED-Based Communication Links. Master's Thesis, Naval Postgraduate School Monterey, CA, USA, April 21, 2020. Online [Accessed 05 December 2021]. https://apps.dtic.mil/sti/pdfs/AD1114685.pdf

[47] T. Hamza, M.-A. Khalighi, S. Bourennane, P. Léon, J. Opderbecke, Investigation of solar noise impact on the performance of underwater wireless optical communication links, Optics Express 24(22) (2016), 25832.

DOI: $\underline{10.1364 / O E .24 .025832}$

[48] R. Amin, B. L. Richards, W. F. X. E. Misa, J. C. Taylor, D. R. Miller, A. K. Rollo, C. Demarke, H. Singh, G. C. Young, J Childress, J. E. Ossolinski, R. T. Reardon, K. H. Koyanagi, The Modular Optical Underwater Survey System. Sensors 17 (2017), 2309.

DOI: $10.3390 / \mathrm{s} 17102309$

[49] N. E. Farr, C. T. Pontbriand, J. D. Ware, L.-P. A. Pelletier, Nonvisible light underwater optical communications, in proceedings of IEEE Third Underwater Communications and Networking Conference (UComms), Lerici, Italy, 2016, pp. 1-4. DOI: $10.1109 / \mathrm{UComms} .2016 .7583454$.

[50] J. Marshall, Vision and lack of vision in the ocean, Current Biology 27(11) (2017), pp. R494-R502. DOI: $10.1016 /$ i.cub.2017.03.012

[51] X. Sun, et al., 375-nm ultraviolet-laser based non-line-of-sight underwater optical communication, Optics express 26(10) (2018), pp. 12870-12877. DOI: $10.1364 /$ OE. 26.012870

[52] X. Sun, X. et al., Non-line-of-sight methodology for high-speed wireless optical communication in highly turbid water, Opt. Comm. 461 (2020) art. no. 125264. DOI: $10.1016 /$ i.optcom.2020.125264

[53] V. Lange, R. Hönl, LED as transmitter and receiver in POF based bidirectional communication systems, in International IEEE Conference and Workshop in Óbuda on Electrical and Power Engineering (CANDO-EPE), 2018, pp. 000137-000142. DOI: $10.1109 /$ CANDO-EPE.2018.8601162

[54] S. Li, A. Pandharipande, F. M. J. Willems, Adaptive visible light communication LED receiver, in Proceeding of 2017 IEEE SENSORS, pp. 1-3. DOI: $10.1109 /$ ICSENS. 2017.8234237

[55] L. Matheus, L. Pires, A. Vieira, L. F. Vieira, M. A. Vieira, J. A. Nacif, The internet of light: Impact of colors in LED-to-LED visible light communication systems, Internet Technology Letters 2(1) (2019), e78. DOI: $10.1002 /$ itl2.78

[56] G. Schirripa Spagnolo, F. Leccese, M. Leccisi, LED as transmitter and receiver of light: A Simple tool to demonstration Photoelectric Effect. Crystals 9(10) (2019) art. no. 531. DOI: $10.3390 /$ crvst 9100531

[57] G. Schirripa Spagnolo, A. Postiglione, I. De Angelis, Simple equipment for teaching internal photoelectric effect, Phys. Educ. 55 (2020) art. no. 055011 DOI: $10.1088 / 1361-6552 / a b 97 b f$

[58] J. Sticklus, P.A. Hoeher, M. Hieronymi, Experimental characterization of single-color power LEDs used as photodetectors, Sensors 20 (2020) art. no. 5200. DOI: $10.3390 / \mathrm{s} 20185200$
[59] M. Galal, W. P. Ng, R. Binns, A. Abd El Aziz, Characterization of RGB LEDs as emitter and photodetector for LED-to-LED communication. In Proceedings of the 12th IEEE/IET International Symposium on Communication Systems, Networks and Digital Signal Processing - CSNDSP, Porto, Portugal, 20-22 July 2020.

DOI: $10.1109 / C S N D S P 49049.2020 .9249617$

[60] M. Galal, W. P. Ng, R. Binns, A. Abd El Aziz, Experimental characterization of RGB LED transceiver in low-complexity LED-to-LED Link, Sensors 20 (2020) art. no. 5754.

DOI: $10.3390 / \mathrm{s} 20205754$

[61] G. Schirripa Spagnolo, F. Leccese, LED rail signals: full hardware realization of apparatus with independent intensity by temperature changes, Electronics 10(11) (2021) art. no. 1291.

DOI: $10.3390 /$ electronics10111291

[62] D. J. Starling, B. Burger, E. Miller, J. Zolnowski, J. Ranalli, An actively quenched single photon detector with a light emitting diode, Modern Applied Science 10(1) (2016) art. no.114. DOI: $10.5539 /$ mas.v10n1p114

[63] L. McCann, Introducing students to single photon detection with a reverse-biased LED in avalanche mode, in 2015 Conference on Laboratory Instruction Beyond the First Year of College, July 2224, College Park, MD, USA.

DOI: $10.1119 /$ bfy.2015.pr.016

[64] S. M. Sze, Kwok K. Ng, Physics of Semiconductor Devices, John Wiley \& Sons, Inc., Hoboken, NJ, USA, 2007. DOI: $10.1002 / 0470068329$

[65] G. Ferrari, M., Sampietro, Wide bandwidth transimpedance amplifier for extremely high sensitivity continuous measurements, Review of scientific instruments 78(9) (2007) art. no. 094703. DOI: $10.1063 / 1.2778626$

[66] F. Zappa, S. Tisa, A. Tosi, S. Cova, Principles and features of single-photon avalanche diode arrays, Sensors and Actuators A: Physical 140(1) (2007), pp. 103-112.

DOI: $10.1016 /$ i.sna.2007.06.021

[67] J. Kirdoda, D. C. S. Dumas, K. Kuzmenko, P. Vines, Z. M. Greener, R. W. Millar, M. M. Mirza, G. S. Buller, D. J. Paul, Geiger mode Ge-on-Si single-photon avalanche diode detectors. 2019 IEEE 16th International Conference on Group IV Photonics (GFP), Singapore, 28-30 Aug 2019

DOI: $\underline{10.1109 / G R O U P 4.2019 .8853918}$

[68] S. Donati, T. Tambosso, Single-photon detectors: from traditional PMT to solid-state SPAD-based technology, IEEE Journal of Selected Topics in Quantum Electronics 20(6) (2014), pp. 204211. DOI: 10.1109 /ISTQE.2014.2350836

[69] C. Wang, H. Y. Yu, Y. J. Zhu, A Long Distance Underwater Visible Light Communication System With Single Photon Avalanche Diode, IEEE Photonics Journal 8(5) (2016) art. no 7906311. DOI: $10.1109 /$ JPHOT.2016.2602330

[70] T. Shafique, O. Amin, M. Abdallah, I. S. Ansari, M. S. Alouini, K. Qaraqe, Performance analysis of single-photon avalanche diode underwater VLC system using ARQ, IEEE Photonics Journal 9(5) (2017), pp. 1-11. DOI: $10.1109 /$ JPHOT.2017.274300

[71] Hadfield, R. Single-photon detectors for optical quantum information applications, Nature Photon 3 (2009), pp. 696-705. DOI: $10.1038 /$ nphoton. 2009.230

[72] D. Chitnis, S. Collins, A SPAD-based photon detecting system for optical communications, Journal of Lightwave Technology 32(10) (2014), pp. 2028-2034.

DOI: $10.1109 / J L T .2014 .2316972$

[73] E. Sarbazi, M. Safari, H. Haas, Statistical modelling of singlephoton avalanche diode receivers for optical wireless communications, IEEE Transactions on Communications 66(9) (2018), pp. 4043-4058. DOI: $10.1109 /$ TCOMM.2018.2822815

[74] T. Shafique, O. Amin, M. Abdallah, I. S. Ansari, M. S. Alouini, K. Qaraqe, Performance analysis of single-photon avalanche diode 
underwater VLC system using ARQ, IEEE Photonics Journal 9(5) (2017), pp. 1-11. DOI: $10.1109 /$ JPHOT.2017.2743007

[75] M. A. Khalighi, T. Hamza, S. Bourennane, P. Léon, J Opderbecke, Underwater wireless optical communications using silicon photo-multipliers, IEEE Photonics Journal 9(4) (2017), pp. $1-10$

DOI: $10.1109 /$ JPHOT.2017.2726565

[76] J. Sticklus, M. Hieronymi, P. A. Hoeher, Effects and constraints of optical filtering on ambient light suppression in LED-based underwater communications, Sensors 18(11) (2018) art. no. 3710. DOI: $\underline{10.3390 / \mathrm{s} 18113710}$

[77] D. Giustiniano, N. O. Tippenhauer, S. Mangold, Low-complexity visible light networking with LED-to-LED communication, in proceedings of 2012 IFIP Wireless Days, 2012 pp. 1-8. DOI: $10.1109 /$ WD. 2012.6402861

[78] G. Schirripa Spagnolo, F. Leccese, System to Monitor IR Radiation of LED Aircraft Warning Lights, 2021 IEEE 8th International Workshop on Metrology for AeroSpace (MetroAeroSpace), 2021, pp. 407-411.

DOI: $10.1109 /$ MetroAeroSpace 51421.2021.9511723

[79] Bivar UV5TZ LEDs Datasheet. Online [Accessed 05 December 2021]

https://www.mouser.it/datasheet/2/50/biva s a0002780821 1 $-2262009 . p d f$

[80] L. K. Gkoura, G. D. Roumelas, H. E. Nistazakis, H. G. Sandalidis, A. Vavoulas, A. D. Tsigopoulos, G. S. Tombras, Underwater Optical Wireless Communication Systems: A Concise Review, Turbulence Modelling Approaches - Current State, Development Prospects, Applications, Konstantin Volkov, IntechOpen, July 26th 2017.

DOI: $10.5772 / 67915$

[81] R. A. Khalil, M. I. Babar, N. Saeed, T. Jan, H. S. Cho, Effect of link misalignment in the optical-Internet of underwater things, Electronics 9(4) (2020) art. no. 646. DOI: $10.3390 /$ electronics 9040646

[82] S. Arnon, D. Kedar, Non-line-of-sight underwater optical wireless communication network, J. Opt. Soc. Am. A 26(3) (2009), pp. 530-539.
DOI: 10.1364 /JOSAA.26.000530

[83] S. Arnon, Underwater optical wireless communication network, Optical Engineering 49(1) (2010) art. no. 015001.

DOI: $10.1117 / 1.3280288$

[84] Linear Technology LT1028 Datasheet. Online [Accessed 05 December 2021]

https://www.analog.com/media/en/technicaldocumentation/data-sheets/1028fd.pdf

[85] A. Ayala, Underwater optical wireless audio transceiver, Senior Project Electrical Engineering Department, California Polytechnic State University, San Luis Obispo (2016). Online [Accessed 05 December 2021]

https://digitalcommons.calpoly.edu/eesp/352/

[86] R. K. Schreyer, G. J. Sonek, An optical transmitter/receiver system for wireless voice communication, IEEE Transactions on Education 35(2) (1992), pp. 138-143. DOI: $\underline{10.1109 / 13.135579}$

[87] J. T. B. Taufik, M. L. Hossain, T. Ahmed, Development of an audio transmission system through an indoor visible light communication link, International Journal of scientific and Research Publications 9(1) (2019) 432-438.

DOI: $10.29322 /$ IJSRP.9.01.2019.p8556

[88] Texas Instruments, Timing circuit NE555 datasheet. Online [Accessed 05 December 2021] https://www.ti.com/lit/ds/symlink/ne555.pdf

[89] Linear Technology, Voltage comparator LT1011. Online [Accessed 05 December 2021] https://www.analog.com/media/en/technicaldocumentation/data-sheets/lt1011.pdf

[90] PWM boost-switching regulator. Online [Accessed 05 December 2021] https://ww1.microchip.com/downloads/en/DeviceDoc/mic32 89.pdf

[91] Audacity ${ }^{\circledR}$ software is copyright (C) 1999-2021 Audacity Team. Web site: https://audacityteam.org/. It is free software distributed under the terms of the GNU General Public License. The name Audacity ${ }^{\circledR}$ is a registered trademark. 